\title{
Pain Medicine Fellowship Program Websites in the United States of America - A Nonparametric Statistic Analysis of I4 Different Criteria
}

\author{
Sahil Gupta $\mathbb{D}^{\prime}$ \\ Scott Palmer ${ }^{2}$ \\ Guilherme Ferreira-Dos- \\ Santos ${ }^{3,4}$ \\ Mark Friedrich Hurdle 2 \\ 'Department of Pain Medicine, Southern \\ Illinois Healthcare, Carbondale, IL, USA; \\ ${ }^{2}$ Department of Pain Medicine, Mayo \\ Clinic, Jacksonville, FL, USA; \\ ${ }^{3}$ Department of Physical Medicine and \\ Rehabilitation, Central Lisbon University \\ Hospital Center, Lisbon, Portugal; \\ ${ }^{4}$ NOVA Medical School, NOVA \\ University of Lisbon, Lisbon, Portugal
}

Correspondence: Sahil Gupta Department of Pain Medicine, Southern Illinois Healthcare, $305 \mathrm{~W}$ jackson St Suite 103, Carbondale, IL, 6290I, USA

Tel + | 618-35|-4972

Fax + 1 618-457-3020

Email sahil.mamc@gmail.com
Objective: To evaluate the content of Pain Medicine Fellowship Program websites in the United States of America.

Methods: We obtained a list of accredited 104 Pain Medicine Fellowship Program websites from the Accreditation Council for Graduate Medical Education and the Electronic Residency Application Service. Individual Pain Medicine Fellowship Program websites were then evaluated on 14 different criteria. We grouped fellowship programs based on census region and Electronic Residency Application Service participation status, and analyzed the differences using nonparametric statistics.

Results: A total of 104 accredited Pain Medicine Fellowship Program websites were evaluated for a total of 14 different criteria. Of the 14 different criteria, an average of 3.94 were described in each website. Number of Fellowship positions per year (71.8\%), clinical rotations during the program (65.1\%), and faculty background (62.2\%) were the most frequently described features on the websites. Night call responsibilities $(3.9 \%)$, meal allowance $(7.8 \%)$ and parking availability $(10.7 \%)$ were the least described features in the websites. There were no significant differences between program websites when grouped by census regions or the participation status in the Electronic Residency Applications Service.

Conclusion: The content of Pain Medicine Fellowship Program websites is extremely variable across the United States of America. This study indicates that there is room for improvement and enhancement of the comprehensiveness of website content for the majority of the programs analyzed. Additionally, this study also emphasizes the importance of having accurate and easily available online information in a post-pandemic era, when prospective fellows evaluate programs online through their websites.

Keywords: ACGME, application, ERAS, fellowship program, pain medicine, website

\section{Plain Language Summary}

Prospective fellows are increasingly using the internet to evaluate training programs before submitting applications for fellowship positions. This study evaluates the content and comprehensiveness of Pain Medicine Fellowship Program websites in the USA based on 14 different criteria. We report that currently there is lack of program information on websites for prospective trainees. Optimization of these resources would help institutions attract the best suited candidates for their programs.

\section{Background}

The internet is an ever-increasing source of information for prospective resident and fellow physicians who want to evaluate training programs when considering their 
future applications, especially in a post-pandemic era. ${ }^{1}$ Therefore, easy accessibility of online information is essential for applicants to know what to expect in each program, from clinical training and research opportunities, to location of training and application requirements. ${ }^{2-5}$ Multiple studies have shown that applicant decisions to apply for, or rank a program, are influenced by its online resources including program websites as well as social media presence. ${ }^{6,7}$ This is even more important for Fellowship programs that accept applicants from several different specialty backgrounds, as is the case of the majority of Pain Medicine Fellowship programs in the United States of America (USA), which accept applicants from Anesthesiology, Neurology, Physical Medicine and Rehabilitation, and Psychiatry, among others. ${ }^{8,9}$

In a pandemic era, when fellowship program directors and candidates have had to reimagine the interview and selection process, it is essential that programs provide comprehensive and accurate information to their prospective applicants through their website, in order to ensure optimal pairing in the Fellowship match. ${ }^{3,5,10}$ Without the opportunity to visit the programs' locations in person, the majority of prospective applicants are primarily and increasingly depending on program websites and virtual interviews to make important decisions about their future clinical training. ${ }^{11}$ Two separate studies have also shown that online resources (e.g. program websites and social media presence) have positively influenced applicant perception of the program which resulted in higher ranking of the program in the rank list order. ${ }^{7,12}$
To our best knowledge, this is the first study to evaluate and report on the comprehensiveness of Pain Medicine Fellowship Program websites in the USA. For this purpose, we reviewed the websites of 104 Pain Medicine Fellowship programs across the USA and evaluated them based on the information offered, including the application process, curriculum and rotations, salary and benefits, faculty profile, among others.

With the detailed evaluation on 14 different criteria presented in this manuscript, we hope to help Pain Fellowship programs update and repurpose their websites to provide comprehensive and easily available information to their prospective applicants.

\section{Methods}

This project evaluated publicly available websites for information about the corresponding Pain Medicine Fellowship programs. The Accreditation Council for Graduate Medical Education (ACGME) and the Electronic Residency Application Service (ERAS) were accessed for a listing of 104 Pain Medicine Fellowship programs in November of 2020. ${ }^{13,14}$ Institutional review board approval was not required prior to the start of the project as this study did not involve human subjects and all information collected was available in the public domain.

Each of the 104 Fellowship Program websites was searched using the Google online search engine, with the strings "name of the institution" and "Pain Medicine Fellowship". All the programs were evaluated for 14 different criteria (Table 1). These criteria have

Table I Left Column Displays the 14 Different Criteria on Which the Pain Medicine Fellowship Program Websites Were Evaluated. Right Side Column Displays the Percentage of Program Websites That Reported Information on Each of the Criteria

\begin{tabular}{|l|c|}
\hline Criteria & Websites Including Information (\%) \\
\hline Number of positions & 71.8 \\
Salary & 29.1 \\
Clinical Rotations & 65.1 \\
International Medical Graduate Eligibility & 21.3 \\
Vacation & 26.2 \\
Call Schedule & 13.6 \\
Night Call Responsibilities & 3.9 \\
Mentorship & 20.3 \\
Alumni and Post fellowship placement & 28.1 \\
Research Funding & 21.4 \\
Parking Availability & 10.7 \\
Meal Allowance & 7.8 \\
Information about location and social events & 10.7 \\
Faculty Medical Background & 62.2 \\
\hline
\end{tabular}


been previously validated by multiple studies which evaluated the content of Residency and Fellowship Program websites across different medical specialties in the USA. $^{3-5,15-17}$ These criteria were also congruent with the needs of the applicants as described in studies in the Plastic Surgery and Internal Medicine literature. ${ }^{18,19}$ The websites were given credit only if the criteria evaluated were either directly addressed on the fellowship website or a direct link was provided to access that information. The presence and absence of content in each of the 14 different categories for each program website was recorded in Microsoft Excel. MannWhitney and Kruskal-Wallis tests were used for statistical analysis using the SPSS v24, with statistical significance set at $\mathrm{P}$-value $<0.05$.

\section{Results}

Of the 104 Pain Medicine Fellowship programs analyzed, 103 (99.3\%) possessed a publicly available website. Analyzed programs were grouped based on the USA census region in Northeast (29 programs), Midwest (27 programs), South (31 programs), and West (17 programs). Review of ERAS data showed that $87(83.6 \%)$ programs participated in a centralized match process while 17 did not.

Individual websites reported a mean of 3.94 (28.1\%) criteria of the 14 different criteria evaluated. Fellowship programs in the West reported an average of 5.35 criteria per program, as compared to Fellowship programs in the Midwest (3.88), Northeast (3.34), and South (3.77). Programs participating in ERAS reported an average of 3.9 criteria per program, as opposed to non-participating programs, which reported 4.1 criteria on average (Table 2). No statistically significant difference was found between the number of criteria included on a program website based on the location of the program or its ERAS participation status. Only 4 programs out of the 104 programs analyzed reported 10 or more criteria on their website. The most commonly reported criteria (Table 1) were the number of fellow positions available per year (71.8\%), curriculum and mandatory clinical rotations $(65.1 \%)$, and faculty profile $(62.2 \%)$. The least reported criteria were night call responsibilities $(3.9 \%)$, meal allowance $(7.8 \%)$, and parking availability (10.7\%).
Table 2 Left Column Displays the Grouping of Pain Medicine Fellowship Program Websites per Census Region and ERAS Participation Status. Right Side Column Displays the Number of Criteria Reported per Group on Average

\begin{tabular}{|l|c|}
\hline $\begin{array}{l}\text { Group Division (Census Region } \\
\text { and ERAS Participation Status) }\end{array}$ & $\begin{array}{c}\text { Number of Criteria } \\
\text { Reported (Mean; (SD)) }\end{array}$ \\
\hline Overall & $3.94(2.58)$ \\
\hline Region & $\mathrm{P}=0.89$ \\
West & $5.35(3.48)$ \\
Midwest & $3.88(2.56)$ \\
Northeast & $3.34(1.91)$ \\
South & $3.77(2.4 \mathrm{I})$ \\
\hline Participating in ERAS & $\mathrm{P}=0.93$ \\
Participating & $3.91(2.65)$ \\
Non-Participating & $4.1 \mathrm{I}(2.26)$ \\
\hline
\end{tabular}

Abbreviation: SD, standard deviation.

\section{Discussion}

To our best knowledge, this is the first study that analyzes the comprehensiveness of Pain Medicine Fellowship Program websites in the USA.

Previous studies published in Anesthesiology and Surgery literature have reported limitations and deficiencies in the amount of information available on Residency and Fellowship Program websites in the USA. ${ }^{3,15,16}$ Our findings are consistent with these earlier studies involving the evaluation of training program websites, which reveal that Residency and Fellowship programs do not maintain comprehensive and updated information on their websites for prospective applicants. This observation was consistent over different geographic areas, as well as the ERAS participation status. ${ }^{17,20}$

This study reveals that only $71.8 \%$ of the programs analyzed had basic information readily available on their websites, such as the number of fellow positions available per year. Other information, like salary, parking availability, or meal allowance was also hard to find or missing altogether. Details on the curriculum, quality of training, vacation, night call responsibilities, and research funding were frequently absent as well. It is likely that this lack of information results in a decrease in applicants' keenness to apply, potentially leading to suboptimal recruitment and Fellowship matching.

A study by Thompson et al showed that International Medical Graduates (IMG) make up about one-third of Pain 
Medicine Fellowship applicants. ${ }^{21}$ In this regard, one of the most important questions concerning applicant eligibility is visa sponsorship. Only $21.3 \%$ of the 104 programs analyzed reported information about visa sponsorship or IMG eligibility on their websites.

When stratifying the data by regions, no statistically significant difference was found between the completeness of Fellowship Program websites in the different USA census regions. This is consistent with website analysis of other training programs. ${ }^{1,16,20}$ When grouped by ERAS participation status, no statistically significant difference was found in the comprehensiveness of the websites' content. This indicates that there is a low-cost, low-risk window of opportunity for improvement for programs to attract better candidates across the USA.

In a subspecialty like Pain Medicine, where the pool of prospective applicants comes from several different medical backgrounds, this study underlines the need to make training program websites useful and easy to navigate. A recent study from Plastic Surgery literature showed that applicants most value information like career placement, faculty profile, curriculum, and research opportunities, when analyzing programs for which to apply for. ${ }^{19}$ We recommend that the information described above be made readily available on the Fellowship Program websites to meet the needs and desires of prospective applicants.

\section{Conclusions}

This study was performed at a critical time, when the pandemic has forced both Fellowship programs and applicants to reimagine the interview and selection process. Traditionally, the application process for a Fellowship Program involved a series of on-site interviews in which selected applicants could see and experience the training program first-hand. However, in a post-pandemic world applicants primarily interview virtually using video conferencing software, which means missing out on the in-person aspect of the traditional interview. Due to such limitations, it is incumbent upon the training programs to provide comprehensive and accurate information on their websites, in order to attract the best suited candidates for their program.

\section{Abbreviations}

ACGME, American Council for Graduate Medical Education; ERAS, Electronic Residency Application Service; IMG, International Medical Graduates; USA, United States of America.

\section{Disclosure}

Dr Mark Friedrich Hurdle reports personal fees from Avanos Medical, outside the submitted work. The authors did not receive any other direct or indirect financial or other benefits for the publication of this manuscript.

\section{References}

1. Charalel RA, Pua BB, Galla N, Trehan SK, Madoff DC. Interventional radiology fellowship website content: what is the relevance to potential applicants? Clin Imaging. 2016;40(6):1070-1074. doi:10.1016/j.clinimag.2016.06.011

2. Mulcahey MK, Gosselin MM, Fadale PD. Evaluation of the content and accessibility of web sites for accredited orthopaedic sports medicine fellowships. J Bone Joint Surg Am. 2013;95(12):e85. doi:10.2106/JBJS.L.00785

3. Chu LF, Young CA, Zamora AK, et al. Self-reported information needs of anesthesia residency applicants and analysis of applicant-related web sites resources at 131 United States training programs. Anesth Analg. 2011;112(2):430-439. doi:10.1213/ ANE.0b013e3182027a94

4. Mahler SA, Wagner MJ, Church A, Sokolosky M, Cline DM. Importance of residency program web sites to emergency medicine applicants. $J$ Emerg Med. 2009;36(1):83-88. doi:10.1016/j. jemermed.2007.10.055

5. Gaeta TJ, Birkhahn RH, Lamont D, Banga N, Bove JJ. Aspects of residency programs' web sites important to student applicants. Acad Emerg Med. 2005;12(1):89-92. doi:10.1197/j.aem.2004.08.047

6. Schweitzer J, Hannan A, Coren J. The role of social networking web sites in influencing residency decisions. $J$ Am Osteopath Assoc. 2012;112(10):673-679.

7. McHugh SM, Shaffer EG, Cormican DS, Beaman ST, Forte PJ, Metro DG. Use of social media resources by applicants during the residency selection process. J Educ Perioperat Med. 2014;16(5): E071.

8. Epstein RH, Dexter F, Pearson ACS. Pain medicine board certification status among physicians performing interventional pain procedures in the State of Florida between 2010 and 2016. Pain Physician. 2020;23(1):E7-e18. doi:10.36076/ppj.2020/23/E7

9. Correll DJ, Kissin I. Academic interest in pain: comparison of four specialties with long-standing involvement in pain medicine. J Anesthes Hist. 2020;6(2):84-89. doi:10.1016/j.janh.2019.08.003

10. Jones RE, Abdelfattah KR. Virtual interviews in the era of COVID-19: a primer for applicants. J Surg Educ. 2020;77 (4):733-734. doi:10.1016/j.jsurg.2020.03.020

11. Rozenshtein A, Griffith BD, Ruchman RB. Residency match during the COVID-19 pandemic: the clear and present danger of the remote interview. $J$ Am Coll Radiol. 2020;18:SS1546-2. doi:10.1016/j. jacr.2020.10.005

12. Irwin TJ, Riesel JN, Ortiz R, Helliwell LA, Lin SJ, Eberlin KR. The impact of social media on plastic surgery residency applicants. Ann Plast Surg. 2021;86(3):335-339. doi:10.1097/ SAP.0000000000002375

13. ACGME; 2021. Available from: https://apps.acgme.org/ads/Public/ Reports/ReportRun. Accessed May 10, 2021

14. ERAS. Pain Medicine (Multidisciplinary); 2021. Available from: https://services.aamc.org/eras/erasstats/par/display.cfm?NAV_ROW= PAR\&SPEC_CD $=530$. Accessed May 10, 2021.

15. Reilly EF, Leibrandt TJ, Zonno AJ, Simpson MC, Morris JB. General surgery residency program websites: usefulness and usability for resident applicants. Curr Surg. 2004;61(2):236-240. doi:10.1016/j. cursur.2003.10.006 
16. Trehan SK, Morrell NT, Akelman E. Accredited hand surgery fellowship web sites: analysis of content and accessibility. J Hand Surg Am. 2015;40(4):778-782. doi:10.1016/j.jhsa.2015.01.024

17. Vilanilam GK, Wadhwa V, Purushothaman R, Desai S, Kamran M, Radvany MG. Critical evaluation of interventional neuroradiology fellowship program websites in North America. World Neurosurg. 2020.

18. Embi PJ, Desai S, Cooney TG. Use and utility of Web-based residency program information: a survey of residency applicants. $J$ Med Internet Res. 2003;5(3):e22. doi:10.2196/jmir.5.3.e22
19. Chen VW, Hoang D, Garner W. Do websites provide what applicants need? Plastic surgery residency program websites versus applicant self-reported needs. Plast Reconstr Surg Glob Open. 2018;6(10): e1900-e. doi:10.1097/GOX.0000000000001900

20. Atia A, Langdell HC, Hollins A, et al. Microsurgery fellowship website and social media presence: are programs optimizing recruitment strategy? J Reconstr Microsurg. 2020.

21. Thompson KM, Neuman S, Schroeder DR, et al. Misrepresentation in multidisciplinary pain medicine fellowship applications to a single academic program. Pain Med. 2015;16(2):274-279. doi:10.1111/pme.12322

\section{Publish your work in this journal}

The Journal of Pain Research is an international, peer reviewed, open access, online journal that welcomes laboratory and clinical findings in the fields of pain research and the prevention and management of pain. Original research, reviews, symposium reports, hypothesis formation and commentaries are all considered for publication. The manuscript

Submit your manuscript here: https://www.dovepress.com/journal-of-pain-research-journa management system is completely online and includes a very quick and fair peer-review system, which is all easy to use. Visit http:// www.dovepress.com/testimonials.php to read real quotes from published authors. 